\title{
$\nabla$ \\ IJCRR \\ Section: Healthcare \\ Perspectives of Medical Students on Medical Education Services during the COVID-19 Pandemic in India
}

Sci. Journal Impact

Factor: 6.1 (2018)

ICV: 90.90 (2018)

\author{
Manasij Mitra ${ }^{1}$, Maitraye Basu²
}

'Professor, Department of Anesthesiology, MGM Medical College and LSK Hospital, Kishanganj, Bihar, India; ${ }^{2}$ Tutor, Department of Biochemistry, MGM Medical College and LSK Hospital, Kishanganj, Bihar, lndia.

\section{ABSTRACT}

Introduction: The COVID-19 pandemic had a disruptive effect on medical education services. Many medical schools curbed clinical interaction and replaced in-person classes with online methods. Baring a few review articles, research articles in this domain are scare. This study was done in the present context to understand the perspectives of the medical students on the different teaching methods adopted and the acceptability of those mechanisms from the view of the end-users is novel.

Materials and Methods: This study was undertaken between 1 May 2020 to 15 May 2020 in 600-bed tertiary care teaching hospital in India having affiliation for both undergraduate and postgraduate medical teaching. A pre-structured questionnaire was randomly distributed to 500 students by sharing a link in the email addresses of the students. Data were entered and analysed in the Microsoft Excel 2010 using descriptive statistics.

Results: So far as the different methods of online teaching are concerned, the Interactive online sessions were attended by $59.5 \%$ of the study respondents, $28.3 \%$ of the study respondents mentioned attending webinars while uploaded lectures were attended by $12.2 \%$ study respondents. $150(57.3 \%)$ of the respondents mentioned that the online training sessions were equally effective as in-person training classes. However, a sizeable proportion of $90(34.3 \%)$ respondents mentioned that the online training sessions were less effective.

Conclusion: Though technology has been rapidly and innovatively used to ensure medical education services continue unhindered, it has thrown up major challenges. These challenges need to be addressed immediately if we need to reap its benefits in future.

Key Words: COVID-19, Medical education services, Online training, In-person training, Medical students

\section{INTRODUCTION}

A case of pneumonia of unknown cause was spotted in $\mathrm{Wu}-$ han, China and reported to the World Health Organisation (WHO) Country Office in China on 31 December 2019. This was the first caseCOVID-19. Since then, the COVID-19 spread across the world. The outbreak was declared by the WHOas a Public Health Emergency of International Concern on 30 January $2020{ }^{1}$

Within one and a half months, the COVID-19 spread rapidly the world over and the WHO declared it a Pandemic on 11 March 2020. ${ }^{2}$

As per the WHO, as on 18 May 2020, the Coronavirus disease (COVID-19) has hit 216 countries, with 4,534,731 confirmed cases the world over and 3,07,537 confirmed deaths. ${ }^{3}$
The situation is no less grave in India with the 56, 316 active cases; 36,823 being cured or discharged and 3, 029 deaths as on 18 May 2020, 08:00 IST (GMT+5:30). ${ }^{4}$

The COVID-19 pandemic also has had a disruptive effect on the health care services not only through the admission of mounting COVID-19 positive cases in hospitals and intensive care units but also because of the scarcity of personal protective equipment, infection of many healthcare workers with the virus and staff exposure to the virus making them and its close contacts go into self-quarantine have to lead to a shortage of healthcare workers. ${ }^{5}$

The COVID-19 crisis also will have a dire economic impact across the world with South-east Asia being hard hit. As per the World Bank Report, South-east Asia may experience its

\section{Corresponding Author:}

Dr. Maitraye Basu, Tutor, Department of Biochemistry, MGM Medical College and LSK Hospital, Kishanganj, Bihar-855107, India ORCID ID: https://orcid.org/0000-0002-2547-2392; Email: maitraye.basu@gmail.com.

ISSN: $2231-2196$ (Print)

Received: 31.05 .2020
ISSN: $0975-5241$ (Online)

Revised: 23.06 .2020
Accepted: 08.07 .2020
Published: 08.08 .2020 
worst economic performance in the last 40 years with many countries slipping into grave recession. Not only did the production sector suffer, but the lockdowns in several countries including India have also had a negative impact and put stress on the service sector too. ${ }^{6}$

The upward slope of the epidemic continues in many places, with the prospects of a resurgence not being a question any more but an anticipated reality with when, where and how bad. Many experts are predicting a potential second wave of COVID-19 in the northern hemisphere this autumn. ${ }^{7}$

Many business sectors have started developing models and strategies to surmount the business crisis and the economic impasse created with an aim towards normalization as much as practical. ${ }^{8}$

The recent trend of medical education has seen a change and the medical schools have been working towards reducing classroom lectures and striking a balance between theory and its practical applications. The medical schools have been using technological advances in the anatomy department and laboratories by replacing conventional ways. The medical schools have been keen on implementing active team-facilitated and self-directed learning vis a vis promoting individualized and inter-professional education. ${ }^{9}$

The COVID-19 pandemic also cast its disruptive effect on medical schools and medical education services. Medical students have an increased chance of contracting or acting as potential vectors for COVID-19 owing to their rotation between departments as a part of their course component. ${ }^{10}$

Many teaching hospitals across the world have suspended medical and observer-ship students from clinical postings. However, despite the prevailing panic and uncertainty created, it is important to learn what history has taught us during pandemic situations. During the severe acute respiratory syndrome (SARS) pandemic at the beginning of the $21^{\text {st }}$ century, through many medical schools in China and Canada officially called off formal teaching onwards and postponed examinations, it leads to the implementation of several innovative initiatives which eventually culminated in the advancement of the medical education. ${ }^{11}$

During this pandemic, many medical schools in India too, have curbed clinical interaction and replaced in-person classes with online methods. Though few review articles predicting the impact of medical education in the light of COVID-19 pandemic exist, research articles in this domain are scared in Indian and even worldwide settings. This study thus was done in the present context to understand the perspectives of the medical students on the different mechanisms adopted and the acceptability of those mechanisms from the view of the end-users is novel. The importance of the findings of this study in future days to come in shaping the medical education curriculum in times of such crisis is also important.

\section{MATERIALS AND METHODS}

We did this study in Bihar in a 600-bed teaching hospital having a capacity to enrol 100 undergraduate medical students each year and affiliation to conduct postgraduate medical education in seventeen disciplines. The hospital has been declared as a designated hospital for COVID-19 positive cases.

This was a cross-sectional online anonymous survey done from 1 May 2020 to 15 May 2020. A pre-structured questionnaire was rolled out by sharing a link in the email addresses of the students. The list of emails of the students was collected from the Medical College Administrative Office. The demographic profile of the medical students like their age, sex, status in the medical education curriculum whether undergraduate or postgraduate and the year as per the medical education curriculum formed the first section of the prestructured questionnaire. The second section consisted of questions concerning the different methods adopted to keep medical education ongoing and the third section focus on questions about the problems encountered by the students during such training and questions seeking their suggestions for further improvement of the teaching methods.

This study was initiated following review and clearance from the Institutional Ethics Committee. The survey link was shared with 500 undergraduate and postgraduate students selected at random from the total student pool. The response rate was a little over $50 \%$. The total number of respondents was 262 .

Data were entered and analysed in the Microsoft Excel 2010 using descriptive statistics.

\section{RESULTS}

The total number of respondents in the study were 262 . The mean age of the study respondents was 21 years ( $\pm 0.84 \mathrm{SD}$ ). As depicted in Figure 1, 60.30\% of the respondents were males while $39.70 \%$ were females.

Undergraduate students consisted of $218(83.2 \%)$ of the study respondents while postgraduate students were only 44 $(16.8 \%)$. The detailed year-wise distribution of the Study respondents is depicted in Table 1.

As per figure 2, so far as the different methods of online teaching are concerned, the Interactive online sessions were attended by $59.5 \%$ of the study respondents, $28.3 \%$ of the study respondents mentioned attending webinars while uploaded lectures were attended by $12.2 \%$ study respondents.

As highlighted in Figure 3, 150 (57.3\%) of the respondents mentioned that the online training sessions were equally effective as in-person training classes while 22 
$(8.4 \%)$ respondents perceived the online training sessions to be more effective. However, a sizeable proportion of $90(34.3 \%)$ respondents mentioned that the online training sessions were less effective.

The various gaps in the online training sessions mentioned by the study respondents have been portrayed in Figure 4 . Missing bedside clinical training, hands-on training and practical sessions have been highlighted by $88.5 \%$, connectivity issues have been raised by $67.2 \%$ of the respondents, less scope of interactive sessions was depicted by $61.8 \%$, $60.3 \%$ mentioned that frequency of classes was less while $26 \%$ respondents perceived that they missed the ambience of the lecture theatre classes.

The various suggestions highlighted by the study respondents have been depicted in Figure 5. These included Splitting the classes into smaller groups; improving internet connectivity and access in the campus, mechanisms to conduct examinations online, single point of contact (coordinator) for the online sessions, provisions for case-based discussion and practical demonstrations online and proposals for video conferences.

The response rate to the question, whether they will voluntarily opt for clinical placements was $236(90.1 \%)$. Among the 236 respondents to this question, $178(75.4 \%)$ answered in the affirmative while only $58(24.6 \%)$ respondents declined the same. All $44(100 \%)$ postgraduate students answered in the affirmative.

\section{DISCUSSIONS}

This teaching hospital suspended all in-person classes for both undergraduate and postgraduate medical students from the third week of March 2020 since the inception of the lockdown initiative undertaken by the Government of India. Proactive management immediately implemented online training sessions to continue with the medical education curriculum. The online classes went on live from 1 April 2020.

This move aligns with the worldwide recent trend and also past experiences during previous pandemics which saw mass cancellation of in-person medical classes, with most being replaced by recorded lectures or live-streams.

As per evidence base, the most realistic solution in the present context is the replacement of in-person training sessions with comparable online methods. However, this could be detrimental as it may lead to loss of the invaluable component of collaborative teaching. This should be kept at the back of the mind. We observed similar observations from the viewpoint of the students in this study.

The need to explore more innovative ways of interactive learning through small group case-based or team-based learn- ing through webinars and teleconferences is felt through the suggestions of the survey respondent expressed the dearth of missing bedside and practical training sessions. This can continue during the COVID-19 pandemic and can be a good future way to bridge the dearth of practical training sessions which are an integral part of the medical education curriculum..$^{9,12}$

This teaching hospital and medical college also had to handle COVID-19 positive cases or attend to quarantined migrant labourers and their family members who came in contact with COVID-19 patients especially in May 2020 owing to the influx of migrant workers from other states.

Since the inception of the lockdown, bedside or OPD based teaching sessions were suspended for all students both undergraduate and postgraduate and clinical postings were suspended for the undergraduate students including the interns. Postgraduate students had their usual postings in the clinical disciplines based on their domain of specialisation. Postgraduate students in the Department of Internal Medicine were posted in the COVID-19 Isolation ward of-course with proper PPE and on a rotation basis to minimise exposure as per the standard guidelines.

Examination for the outgoing batch of postgraduate students in all the disciplines is postponed as on date. The enrolment of the new batch of the first year postgraduate students is also kept on hold in the Medical College instead of the lowdown. As has been pointed out by the study respondents, a sizeable proportion will voluntarily opt for clinical placements. Thus, the medical student workforce can be utilised in clinical domains by imparting focussed training on ventilator settings, use of PPEs and other relevant topics. This will not only lead to the effective utilization of a trained workforce but will not put undue pressure on the existing workforce. Some countries have adopted this model during this COVID-19 pandemic. Decisions to bar the future doctors from clinical placements to reduce exposure can be detrimental instead it may demoralise them. Involving the future doctors in such hours of medical need also reinforces important values, such as altruism, service in times of crisis, and solidarity with the profession. Future doctors who are willing to serve in clinical domains should be given the option to voluntary seek placement in the niche clinical domain of their choice can be a good alternative and also may lead to the effective utilization of the workforce. ${ }^{10}$

The need to look into the options of organising online conferences should also be looked into as conferences are a good knowledge-sharing platform to keep abreast with the advancements and updates in the medical discipline. This is what has been highlighted in this study and also in other articles.

While implementing technology to continue with the medical education during the COVID-19 pandemic is a unique 
way it is fraught with its challenges as is consistent in this study and highlighted in other articles. Though students are more or less comfortable with the online training initiatives, however, lack of ease and problems highlighted reveal that refinements and modifications are needed. Moreover, adaptability to the changing face of medical education in a challenging situation as this, is what the medical students need to demonstrate.

\section{Measures Recommended at the Policy Level}

There is a need to lay down defined guidelines and directives on alternative methods of online training and methods to capture the attendance of the online training sessions at the medical schools in such hours of crisis. The aim should be continuing with the standardized medical education curriculum unabated even in crises like the COVID-19 across the country. Postponing examinations can be demotivating for the outgoing medical students and also act a deterrent to the timely and effective utilization of the trained workforce in such times of crisis. Thus it is also necessary to have standardised online evaluation and examination methods to ensure that examinations are not postponed. Because of the projected second surge of COVID-19 cases in autumn in the northern hemisphere as mentioned above, the need of the hour is to frame a committee, collect feedbacks and good practice sharing from the different Medical Colleges across the country and develop backup strategies to combat the same. The need to address the problems and challenges faced by the medical fraternity is also of paramount importance to ensure that this method of online teaching is comfortable and adaptable to the medical fraternity in future days to come. ${ }^{13}$

\section{CONCLUSION}

The COVID-19 pandemic acted as a major disruptive force for the medical education services across the world and also in our country. Though technology has been rapidly and innovatively used to ensure medical education services continue unhindered and it has brought significant benefits, the major challenges it has thrown up is no less. These challenges need to be addressed immediately if the technological advances used in imparting medical education during the COVID-19 pandemic is to have a positive effect on both the teachers and the students.

It is time for us to rethink and build effective strategies incorporating the latest technological advances to ensure medical education services continue unabated in times of crisis like the COVID-19 pandemic. As each medical student and institution has some novel story to share and with the dearth of research articles in this domain, the need for further research in this domain will be beneficial.

\section{Limitations of the study}

The study shares the viewpoints of the medical students on the different mechanisms used to impart medical education in a particular medical school and thus the generalization of the findings may not be appropriate.

\section{Conflict of Interest}

The authors declare there is no conflict of interest.

\section{Special acknowledgement}

We thank Dr Dilip Kumar Jaiswal, the Director, MGM Medical College and LSK Hospital, Kishanganj, Bihar and Dr Ichchit Bharat, Registrar, MGM Medical College and LSK Hospital, Kishanganj, Bihar for supporting the teachers and students by providing the platform to continue with the medical education during this pandemic and also motivating the researchers in conducting this study.

We also thank the students of MGM Medical College and LSK, Hospital who took their time out to answer to the research questionnaire.

Authors acknowledge the immense help received from the scholars whose articles are cited and included in references to this manuscript. The authors are also grateful to authors/ editors/publishers of all those articles, journals and books from where the literature for this article has been reviewed and discussed.

\section{REFERENCE}

1. Rolling updates on coronavirus disease (COVID-19). Summary. Available at https://www.who.int/emergencies/diseases/novelcoronavirus-2019/events-as-they-happen. Accessed on 18 May 2020.

2. WHO Director-General's opening remarks at the media briefing on COVID-19 - 11 March 2020. Available at https://www.who. int/dg/speeches/detail/who-director-general-s-opening-remarksat-the-media-briefing-on-covid-19---11-march-2020. Accessed on 18 May 2020.

3. Coronavirus disease (COVID-19) outbreak situation. Available at https://www.who.int/emergencies/diseases/novel-coronavirus-2019? gclid=EAIaIQobChMI8fPrluu86QIVB2oqCh2AfgyR EAAYASAAEgLLhfD_BwE. Accessed on 18 May 2020.

4. Covid-19 India. Available at https://www.mohfw.gov.in/. Accessed on 18 May 2020.

5. Susan Mayor. COVID-19: impact on cancer workforce and delivery of care. Published Online April 20, 2020 https://doi. org/10.1016/ S1470-2045(20)30240-0.

6. World Bank. 2020. "Public Banks" South Asia Economic Focus (April), World Bank, Washington, DC. Doi: 10.1596/9781-4648-1566-9.

7. Lena H. Sun, "CDC director warns second wave of coronavirus is likely to be even more devastating," Washington Post, April 21, 2020, washingtonpost.com.

8. COVID-19: Implications for business. May 13, 2020- Executive Briefing. Available at https://www.mckinsey.com/businessfunctions/risk/our-insights/covid-19-implications-for-business. Accessed on 18 May 2020. 
9. Rose S. Medical Student Education in the Time of COVID-19. JAMA. Published online March 31, 2020. doi:10.1001/ jama.2020.5227.

10. Miller DG, Pierson L, Doernberg S. The Role of Medical Students During the COVID-19 Pandemic [published online ahead of print, 2020 Apr 7]. Ann Intern Med. 2020;M20-1281. doi:10.7326/M20-1281.

11. Hanad Ahmed, Mohammed Allaf, Hussein Elghazaly. COVID-19 and medical education. Lancet Infect Dis 2020 Pub-

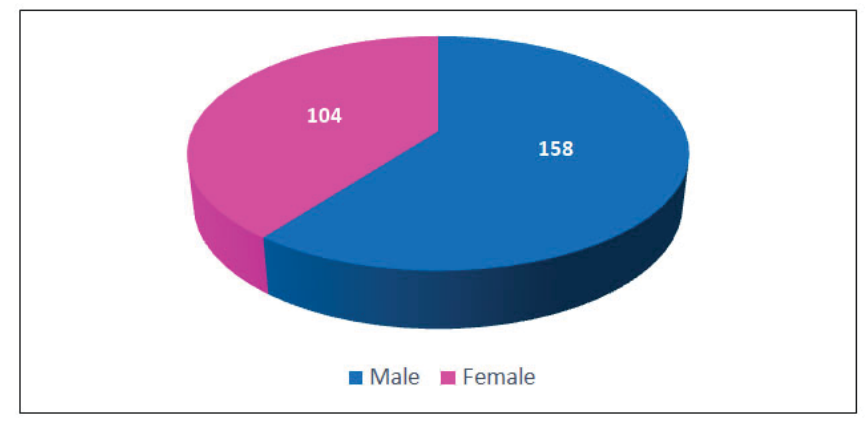

Figure 1: Sex Distribution of the Survey Respondents.

Table 1: Table showing the Composition of the Survey Respondents

\begin{tabular}{lc} 
Undergraduate & $218(83.2 \%)$ \\
$1^{\text {st }}$ Year students & $42(19.3 \%)$ \\
$2^{\text {nd }}$ Year Students & $35(16 \%)$ \\
$3^{\text {rd }}$ Year Students & $53(24.3 \%)$ \\
$4^{\text {th }}$ Year Students & $48(22 \%)$ \\
$5^{\text {th }}$ Year Students and Interns & $40(18.4 \%)$ \\
Postgraduate & $44(16.8 \%)$ \\
$1^{\text {st }}$ year Students & $20(45.5 \%)$ \\
$2^{\text {nd }}$ Year Students & $16(36.4 \%)$ \\
$3^{\text {rd }}$ Year Students & $8(18.1 \%)$ \\
\hline
\end{tabular}

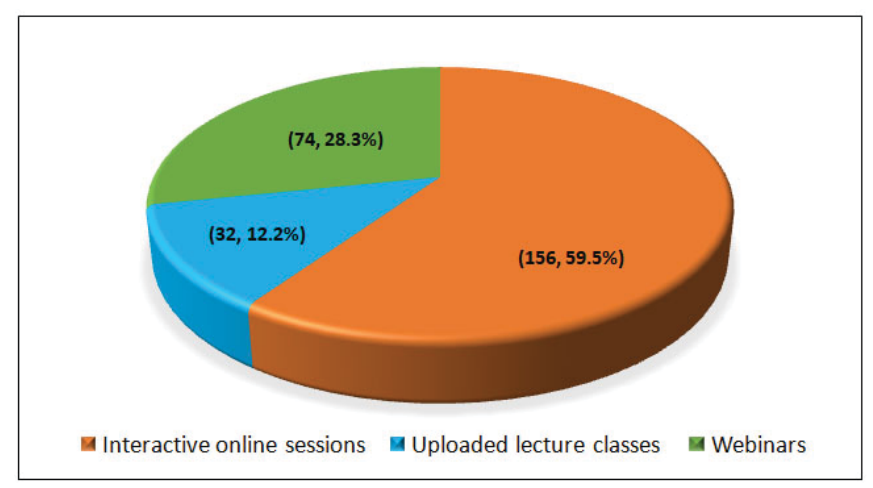

Figure 2: OnlineTeaching Method attended as mentioned by the Study Respondents. lished Online March 23, 2020. https://doi.org/10.1016/ S14733099(20)30226-7. Accessed on 17 May 2020.

12. Ferrel M N, Ryan J J (March 31, 2020) The Impact of COVID-19 on Medical Education. Cureus 12(3): e7492. doi:10.7759/ cureus.7492.

13. Goh P, Sandars J, 2020, 'A vision of the use of technology in medical education after the COVID-19 pandemic', MedEdPublish, 9, [1], 49, https://doi.org/10.15694/mep.2020.000049.1

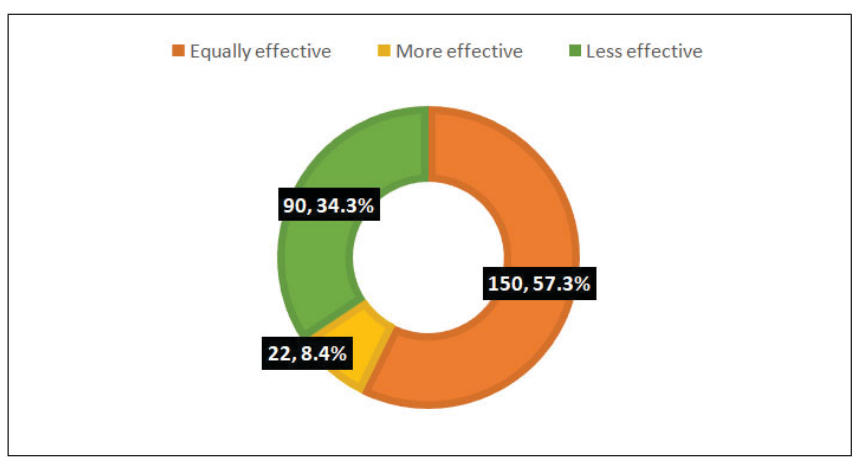

Figure 3: Effectivity of the online training sessions as perceived by the Study Respondents.

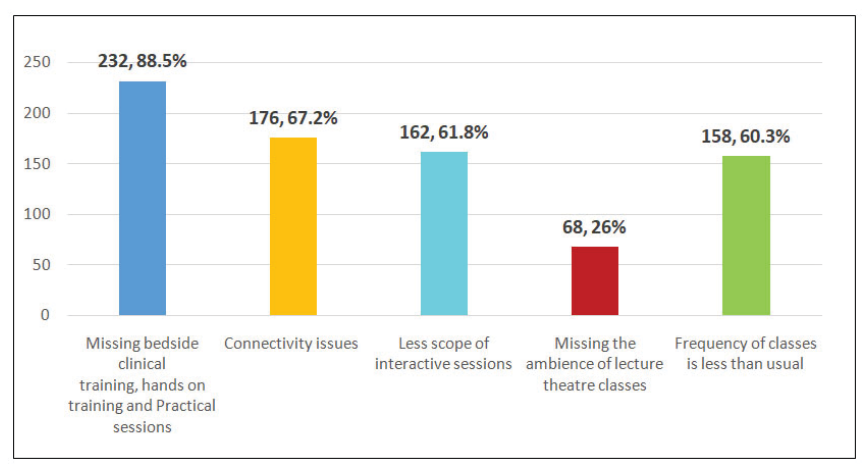

Figure 4: Lacunae in the Online Training Sessions as perceived by the Study Respondents.

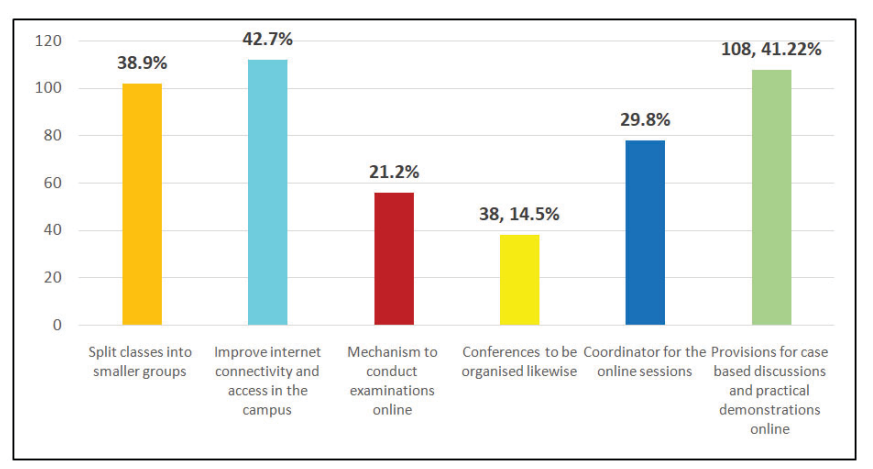

Figure 5: Suggestions to Improve the Online Training Sessions. 